\title{
Metabolic markers associated with insulin resistance predict type 2 diabetes in Koreans with normal blood pressure or prehypertension
}

\author{
Ki-Chul Sung ${ }^{1 *}$, Hyun-Young Park ${ }^{2}$, Min-Ju Kim² and Gerald Reaven ${ }^{3}$
}

\begin{abstract}
Background: Questions remain as to the association between essential hypertension and increased incidence of type 2 diabetes (T2DM). The premise of this analysis is that insulin resistance/compensatory hyperinsulinemia is a major predictor of T2DM, and the greater the prevalence of insulin resistance within any population, normotensive or hypertensive, the more likely T2DM will develop. The hypothesis to be tested is that surrogate estimates of insulin resistance will predict incident T2DM to a significant degree in persons with normal blood pressure or prehypertension.
\end{abstract}

Methods: Analysis of data from a population-based survey of 10,038 inhabitants of rural and urban areas of Korea, $\geq 40$ years-old, initiated in 2001, with measures of demographic and metabolic characteristics at baseline and 8-years later. Participants were classified as having normal blood pressure or prehypertension, and three simple manifestations of insulin resistance related to the pathophysiology of T2DM used to predict incident T2DM: (1) glycemia (plasma glucose concentration 2-hour after $75 \mathrm{~g}$ oral glucose challenge $=2$-hour PG); (2) hyperinsulinemia (plasma insulin concentration 2-hour after $75 \mathrm{~g}$ oral glucose challenge $=2$-hour PI); and (3) dyslipidemia (ratio of fasting plasma triglyceride/high/density lipoprotein cholesterol concentration $=\mathrm{TG} / \mathrm{HDL}-\mathrm{C}$ ratio).

Results: Fully adjusted hazard ratios $(\mathrm{HR}, 95 \% \mathrm{Cl})$ for incident T2DM were highest $(\mathrm{P}<0.001)$ in the quartile of individuals with the highest 2-hour PG concentrations, ranging from 5.84 (3.37-10.1) in women with prehypertension to 12.2 (7.12-21.00) in men with normal blood pressure. T2DM also developed to a significantly greater degree in subjects within the highest quartile of TG/HDL-C ratios, with HRs varying from 2.91 (1.63-2.58) in women with prehypertension $(P<0.001)$ to $1.77(1.12-2.81, P<0.05)$ in men with prehypertension. The least predictive index of insulin resistance was the 2 -hour PI concentration. Subjects with normal blood pressure in the highest quartile of 2-hour PI concentrations were significantly associated with incident T2DM, with HRs of $1.5(1.02-2.20, P=0.25)$ and $2.02(1.35-3.02, P<0.001)$, in men and women, respectively. Finally, incidence of T2DM in the highest quartile was somewhat greater in patients with prehypertension, irrespective of predictor.

Conclusions: Metabolic variables associated with insulin resistance (glycemia, insulinemia, and dyslipidemia) predict the development of T2DM in patients with either normal blood pressure or prehypertension.

Keyword: Type 2 diabetes insulin resistance TG/HDL-C ratio prehypertension

\footnotetext{
*Correspondence: kcmd.sung@samsung.com

${ }^{1}$ Division of Cardiology, Department of Medicine, Kangbuk Samsung

Hospital, Sungkyunkwan University School of Medicine, \#108, Pyung

Dong, Jongro-Ku, Seoul 110-746, Republic of Korea

Full list of author information is available at the end of the article
} 


\section{Background}

In a recent publication, Emdin and colleagues pointedout that despite biological rationale for a relationship between elevated blood pressure and incident type 2 diabetes (T2DM), 12 of 30 cohort studies reviewed could not identify evidence of this association. Furthermore, the remaining 18 studies "reported a considerably variable strength of association [1]". In an effort to obtain a more definitive view of the putative association between elevated blood pressure and T2DM, they analyzed medical records of 4.1 million individuals, free of hypertension and T2DM, in a U.K. primary care setting, as well as performing a meta-analysis of existing prospective studies. The results of their analysis documented a significant association between elevations of blood pressure and T2DM, and concluded that "further investigation is needed to determine whether this association is causal."

The association between elevated blood pressure and T2DM is not limited to inhabitants of the U.K., and results of the recent Korean Genome and Epidemiological Study have demonstrated that this relationship also exists in patients with prehypertension [2]. Assuming the presence of an association between elevations in blood pressure and T2DM, it remains to be seen, as pointed out by Emdin, et al. [1], if the two abnormalities are causally related. The overall hypothesis underlying this analysis is that the association between hypertension and T2DM is causal in nature, and related to the role of insulin resistance as a major risk factor in the genesis of both hypertension and T2DM [3-5]. Put most simply, insulin resistance is a predictor of T2DM $[3,4]$, and the greater the prevalence of this defect in a population [5], the more at risk of T2DM they will be. The more specific hypothesis underlying this analysis is that surrogate estimates of insulin resistance will predict incident T2DM not only in a normal population, but also in patients with prehypertension.

\section{Methods}

\section{Study participants}

The Korean Genome and Epidemiology Study [2], a population-based prospective cohort study, was initiated to investigate prevalence in Korea of risk factors for chronic disease, as well as incident disease. The survey began in 2001-2002, included 10,038 participants $\geq 40$ years of age, and follow-up examinations were performed every 2 years. Specimens have been collected from residents in both rural (Anseong) and urban (Ansan) areas. Baseline and 8-year follow-up data were obtained from the Center for Genome Science in the National Institute of Health, Korea. Details of the present cohort have been described elsewhere [6]. Of the initial cohort, complete data were available on 5697 participants classified at baseline as having normal blood pressure $(\mathrm{n}=3930)$ or prehypertension $(\mathrm{n}=1767)$, and analysis of these data form the substance of this report (Fig. 1). The study protocol was approved by the Institutional Review Board of the Korea Centers for Disease Control and Prevention, and written informed consent was obtained from all participants.

\section{Demographic and metabolic measurements}

Waist circumference (WC) was measured at the midpoint between the ribs and the iliac crest in the standing position. Body weight and height were measured to the nearest $0.1 \mathrm{~kg}$ and $0.1 \mathrm{~cm}$, with body mass index (BMI) calculated as weight $(\mathrm{kg})$ divided by height $\left(\mathrm{m}^{2}\right)$. BP was measured after a $5 \mathrm{~min}$ rest period in the supine position, with measurements taken at least twice at 30-s intervals and averaged. Blood samples were collected after at least an $8 \mathrm{~h}$ fast. Plasma glucose (PG), total cholesterol, highdensity lipoprotein cholesterol (HDL-C), and triglyceride (TG) concentrations were measured enzymatically, and low-density lipoprotein cholesterol concentrations estimated by the Friedwald formula [7] Plasma insulin (PI) concentrations were measured by radioimmunoassay and hemoglobin $\mathrm{A} 1 \mathrm{C}(\mathrm{HbA} 1 \mathrm{C})$ concentrations by high-performance liquid chromatography.

\section{Definition of diabetes mellitus and hypertension}

Diabetes mellitus was diagnosed according to criteria of the American Diabetes Association as either a fasting PG $\geq 126 \mathrm{mg} / \mathrm{dL}$, a PG concentration $\geq 200 \mathrm{mg} / \mathrm{dL}$ 2-hours after an oral glucose challenge, an $\mathrm{HbA} 1 \mathrm{C} \geq 6.5 \%$, or use of an oral hypoglycemic agent [8]. Participants were classified

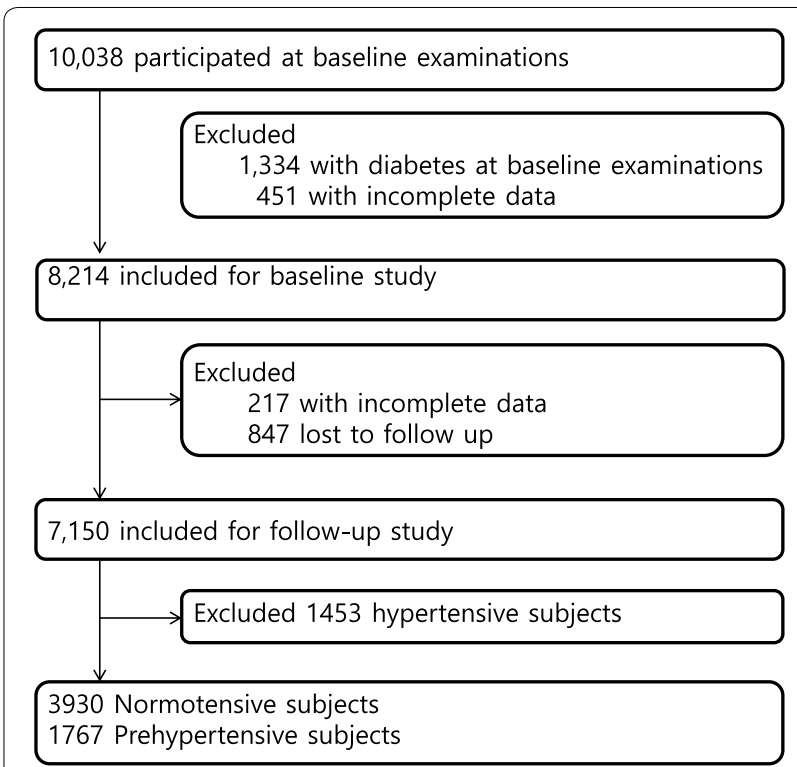

Fig. 1 Study flow chart showing subjects screened, included and followed up 
according to the Seventh Report of the Joint National Committee Prevention, Detection, Evaluation, and Treatment of High Blood Pressure [9] as having normal blood pressure ( $<120 \mathrm{~mm} \mathrm{Hg}$ systolic and $<80 \mathrm{~mm} \mathrm{Hg}$ diastolic) or prehypertension (120-139 mm Hg systolic or $80-89 \mathrm{~mm} \mathrm{Hg}$ diastolic). The 1453 participants considered to have hypertension at baseline, based upon an elevated blood pressure ( $\geq 40 \mathrm{~mm} \mathrm{Hg}$ systolic or $\geq 90 \mathrm{~mm} \mathrm{Hg}$ diastolic) or use of blood pressure-lowering medication, were excluded from further analysis to avoid the possible adverse effects of hypertension-related peripheral vascular disease on insulin resistance as contributing to their $21 \%$ incidence of T2DM.

\section{Surrogate estimates of insulin resistance}

The ability of three different manifestations of insulin resistance to identify enhanced risk of T2DM in participants with either normal BP or prehypertension at baseline was evaluated.

1. 2-hour PG: PG concentration 2-hours after an oral glucose challenge to estimate the degree to which the overall glycemic status has decompensated in the face of a decrease in insulin action.

2. 2-hour PI: PI concentration 2-hours after an oral glucose challenge to estimate compensatory insulin response in the face of insulin resistance $[10,11]$.

3. Fasting plasma TG/HDL-C ratio: lipid factors associated with insulin resistance, known to be significantly correlated with insulin resistance and adverse clinical outcome [12-15].

\section{Statistical analysis}

Distribution testing for normality was performed using the Shapiro-Wilk test, with the data log-transformed to obtain normalized distributions. The baseline characteristics of subjects were expressed as mean \pm S.D., or geometric means with $95 \%$ confidence intervals (CIs). Differences between groups were compared by oneway analysis of variance for continuous variables and $x^{2}$ tests for categorical variables. The geometric means of log-transformed variables were back-transformed for ease of interpretation and reported with their $95 \%$ CIs. Diabetes incidence rate was calculated per 1000 personyears for 2-hour PG, 2-hour PI, and plasma TG/HDL-C concentration ratio. Cox proportional hazards models were used to analyze time at risk and the association, HOMA-IR, 2-hour insulin, and TG/HDL-C ratio, and reported as hazard ratios (HRs) and $95 \%$ CIs. Participants with 1st quartile of each variable at baseline were considered the reference group. Values of $\mathrm{P}<0.05$ were considered statistically significant. All data were analyzed using SPSS software (version 21.0; SPSS, Chicago, IL, USA).

\section{Results}

Baseline demographic and metabolic characteristics in the total experimental population are presented in Table 1. In addition, Table 1 contains comparison of these experimental variables in the normal and prehypertension subgroups. These data indicate that patients with prehypertension were older, with higher values for

Table 1 Comparison of baseline characteristics among participants with normal blood pressure and prehypertension

\begin{tabular}{|c|c|c|c|c|}
\hline Variable & All $(n=5697)$ & Normal BP $(n=3930)$ & Prehypertension ( $n=1767$ ) & $P$ value \\
\hline Age (year) & $50.6 \pm 8.5$ & $49.3 \pm 7.9$ & $53.6 \pm 8.9$ & $<0.001$ \\
\hline BMI (kg/m2) & $24.1 \pm 3.0$ & $23.9 \pm 2.9$ & $24.6 \pm 3.1$ & $<0.001$ \\
\hline$W C(\mathrm{~cm})$ & $81.1 \pm 8.4$ & $80.0 \pm 8.2$ & $83.6 \pm 8.5$ & $<0.001$ \\
\hline $\mathrm{SBP}(\mathrm{mmHg})$ & $110.4 \pm 12.5$ & $104.3 \pm 9.0$ & $124.1 \pm 7.2$ & $<0.001$ \\
\hline $\mathrm{DBP}(\mathrm{mmHg})$ & $71.3 \pm 9.1$ & $67.5 \pm 7.7$ & $79.8 \pm 5.6$ & $<0.001$ \\
\hline $\mathrm{FPG}(\mathrm{mg} / \mathrm{dL})$ & $82.4 \pm 8.3$ & $81.9 \pm 8.1$ & $83.5 \pm 8.7$ & $<0.001$ \\
\hline 2-hour PG (mg/dL) & $112.0 \pm 29.5$ & $111.2 \pm 28.9$ & $113.7 \pm 30.9$ & 0.003 \\
\hline $\mathrm{FPI}(\mu \mathrm{IU} / \mathrm{mL})$ & $7.34 \pm 4.83$ & $7.18 \pm 4.67$ & $7.71 \pm 5.15$ & $<0.001$ \\
\hline 2-hour PI ( $\mu \mathrm{U} / \mathrm{mL})$ & $26.4 \pm 24.6$ & $26.2 \pm 24.0$ & $26.8 \pm 25.9$ & 0.354 \\
\hline HOMA-IR & $1.50 \pm 1.01$ & $1.46 \pm 0.97$ & $1.59 \pm 1.10$ & $<0.001$ \\
\hline Hemoglobin A1C (\%) & $5.52 \pm 0.34$ & $5.50 \pm 0.33$ & $5.57 \pm 0.35$ & $<0.001$ \\
\hline $\mathrm{TC}(\mathrm{mg} / \mathrm{dL})$ & $188.0 \pm 33.2$ & $186.3 \pm 32.4$ & $191.7 \pm 34.8$ & $<0.001$ \\
\hline $\mathrm{HDL}-\mathrm{C}(\mathrm{mg} / \mathrm{dL})$ & $45.3 \pm 9.9$ & $45.3 \pm 9.7$ & $45.4 \pm 10.2$ & 0.845 \\
\hline LDL-C (mg/dL) & $114.5 \pm 30.6$ & $114.1 \pm 29.6$ & $115.5 \pm 32.7$ & 0.105 \\
\hline $\mathrm{TG}(\mathrm{mg} / \mathrm{dL})$ & $140.6 \pm 64.6$ & $134.5 \pm 61.5$ & $154.1 \pm 69.0$ & $<0.001$ \\
\hline TG/HDL-C & $3.38 \pm 2.04$ & $3.23 \pm 1.95$ & $3.70 \pm 2.19$ & $<0.001$ \\
\hline
\end{tabular}

The data are expressed as mean \pm standard deviation. Statistical differences between groups were compared with one-way ANOVA

$B M I$ body mass index, WC waist circumference, SBP systolic blood pressure, DBP diastolic blood pressure, FPG fasting plasma glucose, 2-hour $P G$ plasma glucose 2-hours post-glucose challenge, FPI fasting insulin, 2-hour PI plasma insulin 2-hours post-glucose challenge, HOMA-IR homeostatic model for insulin resistance, TC total cholesterol, HDL-C high-density-lipoprotein cholesterol, LDL-C low-density lipoprotein cholesterol, TG triglyceride 
body mass index and waist circumference, and higher blood pressures. With the exception of the 2-hour plasma insulin, high-density lipoprotein cholesterol, and low-density lipoprotein concentration, the values were all other metabolic variables were higher in those with prehypertension.

Table 2 presents the sex-stratified risk for incident T2DM in normal subjects and patients with prehypertension divided into quartiles of the on the basis of their 2-hour PG concentration. Incident T2DM was greatest in the highest quartile of those with prehypertension in both men ( 43 vs. $31 \%$ ) and women (37 vs. $25 \%$ ). In general, the higher the quartile, the greater the fully adjusted HR, varying in quartile 4 from $5.84(3.37-10.1)$ in prehypertensive women to $12.2(7.12-21.0)$ in men with normal blood pressure (all $\mathrm{P}<0.001$ ).

Table 3 contains a similar comparison, but in this case the quartiles were created as a function of the magnitude of the TG/HDL-C ratio. Incident T2DM was again greatest in the highest quartile of those with prehypertension in both men (24 vs. $18 \%$ ) and women ( 24 vs. $16 \%)$. When compared to the 2-hour PG, the actual values of the HRs were lower when the TG/HDL-C ratio was used to predict incident T2DM. However, the HRs in the upper quartile and incident T2DM remained statistically significantly associated in the fully adjusted model in both experimental groups and in men and women.

Table 4 depicts the sex-stratified risk for incident T2DM when persons with normal blood pressure and patients with prehypertension were stratified into quartiles on the basis of their 2-hour PI concentration. As before, incident T2DM occurred more commonly in men ( 26 vs. $18 \%$ ) and women ( 20 vs. $15 \%$ ) with prehypertension. Although this manifestation of insulin resistance predictor was the least powerful in identifying incident T2DM, the fully adjusted model still detected a significant trend $(\mathrm{P}<0.05)$ between magnitude of 2-hour PI and incident T2DM in both populations and $\mathrm{n}$ men and women. Furthermore, the HR of the quartile with the highest 2-hour PI concentration (quartile 4) was still

Table 2 Sex-stratified risk for incident diabetes by quartile of 2-hour plasma glucose among participants with normal blood pressure and prehypertension

\begin{tabular}{|c|c|c|c|c|c|c|c|c|}
\hline & \multirow{2}{*}{$\begin{array}{l}\text { Number } \\
\text { at risk }\end{array}$} & \multirow[t]{2}{*}{ Diabetes cases } & \multicolumn{2}{|l|}{ Unadjusted } & \multicolumn{2}{|l|}{ Model 1} & \multicolumn{2}{|l|}{ Model 2} \\
\hline & & & HR (95 \% Cl) & P for trend & HR (95 \% Cl) & P for trend & HR (95 \% Cl) & P for trend \\
\hline \multicolumn{9}{|l|}{ Normal BP } \\
\hline \multicolumn{9}{|l|}{ Men } \\
\hline Quartile 1 & 462 & 15 & 1 (reference) & $<0.001$ & 1 (reference) & $<0.001$ & 1 (reference) & $<0.001$ \\
\hline Quartile 2 & 428 & 29 & $2.08(1.12-3.88)^{*}$ & & $2.08(1.12-3.88)^{*}$ & & $2.07(1.11-3.86)^{*}$ & \\
\hline Quartile 3 & 439 & 45 & $3.20(1.78-5.74)^{* *}$ & & $3.20(1.78-5.73)^{* *}$ & & $3.28(1.82-5.90)^{* *}$ & \\
\hline Quartile 4 & 443 & 138 & $11.8(6.95-20.2)^{* *}$ & & $11.8(6.94-20.2)^{* *}$ & & $12.2(7.12-21.0)^{* *}$ & \\
\hline \multicolumn{9}{|l|}{ Women } \\
\hline Quartile 1 & 555 & 18 & 1 (reference) & $<0.001$ & 1 (reference) & $<0.001$ & 1 (reference) & $<0.001$ \\
\hline Quartile 2 & 562 & 23 & $1.32(0.71-2.45)$ & & $1.30(0.70-2.40)$ & & $1.27(0.68-2.35)$ & \\
\hline Quartile 3 & 521 & 41 & $2.52(1.45-4.39)^{*}$ & & $2.45(1.41-4.27)^{*}$ & & $2.24(1.28-3.91)^{*}$ & \\
\hline Quartile 4 & 517 & 130 & $9.04(5.52-14.8)^{* *}$ & & $8.76(5.35-14.4)^{* *}$ & & $8.10(4.92-13.3)^{* *}$ & \\
\hline \multicolumn{9}{|c|}{ Prehypertension } \\
\hline \multicolumn{9}{|l|}{ Men } \\
\hline Quartile 1 & 238 & 12 & 1 (reference) & $<0.001$ & 1 (reference) & $<0.001$ & 1 (reference) & $<0.001$ \\
\hline Quartile 2 & 246 & 21 & $1.66(0.82-3.38)$ & & $1.68(0.83-3.42)$ & & $1.60(0.79-3.26)$ & \\
\hline Quartile 3 & 235 & 36 & $3.26(1.70-6.27)^{* *}$ & & $3.21(1.67-6.17)^{* *}$ & & $3.09(1.60-5.95)^{*}$ & \\
\hline Quartile 4 & 230 & 99 & $10.4(5.72-19.0)^{* *}$ & & $10.5(5.75-19.1)^{* *}$ & & $9.96(5.44-18.2)^{* *}$ & \\
\hline \multicolumn{9}{|l|}{ Women } \\
\hline Quartile 1 & 213 & 16 & 1 (reference) & $<0.001$ & 1 (reference) & $<0.001$ & 1 (reference) & $<0.001$ \\
\hline Quartile 2 & 197 & 10 & $0.71(0.32-1.57)$ & & $0.72(0.33-1.58)$ & & $0.70(0.32-1.54)$ & \\
\hline Quartile 3 & 209 & 28 & $1.84(0.99-3.40)$ & & $1.83(0.99-3.39)$ & & $1.78(0.96-3.30)$ & \\
\hline Quartile 4 & 199 & 73 & $6.16(3.58-10.6)^{* *}$ & & $6.13(3.56-10.5)^{* *}$ & & $5.84(3.37-10.1)^{* *}$ & \\
\hline
\end{tabular}

Model 1: adjusted for age

Model 2: adjusted for the variables in model 1 and body mass index, family history of diabetes (yes or no), education (less than high school, high school or equivalent, or college or above), alcohol use (current or non-current), and smoking status (current or non-current)

${ }^{*} P<0.05$, ${ }^{*} P<0.001$ 
Table 3 Sex-stratified risk for incident diabetes by quartile of TG/HDL-C among participants with normal blood pressure and prehypertension

\begin{tabular}{|c|c|c|c|c|c|c|c|c|}
\hline & \multirow{2}{*}{$\begin{array}{l}\text { Number } \\
\text { at risk }\end{array}$} & \multirow{2}{*}{$\begin{array}{l}\text { Diabetes } \\
\text { cases }\end{array}$} & \multicolumn{2}{|l|}{ Unadjusted } & \multicolumn{2}{|l|}{ Model 1} & \multicolumn{2}{|l|}{ Model 2} \\
\hline & & & HR (95 \% Cl) & $P$ for trend & HR (95 \% Cl) & P for trend & HR (95 \% Cl) & P for trend \\
\hline \multicolumn{9}{|l|}{ Normal BP } \\
\hline \multicolumn{9}{|l|}{ Men } \\
\hline Quartile 1 & 443 & 39 & 1 (reference) & $<0.001$ & 1 (reference) & $<0.001$ & 1 (reference) & $<0.001$ \\
\hline Quartile 2 & 444 & 47 & $1.15(0.75-1.76)$ & & $1.16(0.76-1.77)$ & & $1.18(0.77-1.81)$ & \\
\hline Quartile 3 & 444 & 61 & $1.53(1.02-2.28)^{*}$ & & $1.54(1.03-2.30)^{*}$ & & $1.54(1.02-2.32)^{*}$ & \\
\hline Quartile 4 & 443 & 82 & $2.16(1.47-3.16)^{* *}$ & & $2.21(1.51-3.23)^{* *}$ & & $2.08(1.39-3.12)^{* *}$ & \\
\hline \multicolumn{9}{|l|}{ Women } \\
\hline Quartile 1 & 539 & 32 & 1 (reference) & $<0.001$ & 1 (reference) & $<0.001$ & 1 (reference) & $<0.001$ \\
\hline Quartile 2 & 539 & 44 & $1.43(0.91-2.27)$ & & $1.41(0.89-2.23)$ & & $1.55(0.98-2.46)$ & \\
\hline Quartile 3 & 539 & 49 & $1.60(1.02-2.51)^{*}$ & & $1.53(0.98-2.41)$ & & $1.63(1.03-2.57)^{*}$ & \\
\hline Quartile 4 & 539 & 88 & $3.00(1.97-4.47)^{* *}$ & & $2.72(1.80-4.12)^{*}$ & & $2.58(1.70-3.94)^{* *}$ & \\
\hline \multicolumn{9}{|c|}{ Prehypertension } \\
\hline \multicolumn{9}{|l|}{ Men } \\
\hline Quartile 1 & 237 & 37 & 1 (reference) & $<0.001$ & 1 (reference) & $<0.001$ & 1 (reference) & $<0.001$ \\
\hline Quartile 2 & 237 & 37 & $0.92(0.58-1.45)$ & & $0.93(0.59-1.46)$ & & $0.96(0.60-1.54)$ & \\
\hline Quartile 3 & 238 & 37 & $0.98(0.62-1.55)$ & & $1.01(0.64-1.59)$ & & $1.03(0.63-1.68)$ & \\
\hline Quartile 4 & 237 & 57 & $1.54(1.02-2.33)^{*}$ & & $1.65(1.09-2.50)^{*}$ & & $1.77(1.12-2.81)^{*}$ & \\
\hline \multicolumn{9}{|l|}{ Women } \\
\hline Quartile 1 & 206 & 16 & 1 (reference) & $<0.001$ & 1 (reference) & $<0.001$ & 1 (reference) & $<0.001$ \\
\hline Quartile 2 & 203 & 22 & $1.39(0.73-2.65)$ & & $1.39(0.73-2.64)$ & & $1.35(0.70-2.59)$ & \\
\hline Quartile 3 & 205 & 41 & $2.78(1.56-4.96)^{*}$ & & $2.76(1.55-4.92)^{*}$ & & $2.66(1.47-4.79)^{*}$ & \\
\hline Quartile 4 & 204 & 48 & $3.23(1.83-5.69)^{* *}$ & & $3.18(1.80-5.62)^{* *}$ & & $2.91(1.63-5.18)^{* *}$ & \\
\hline
\end{tabular}

Model 1: adjusted for age

Model 2: adjusted for the variables in model 1 and fasting plasma glucose, body mass index, family history of diabetes (yes or no), education (less than high school, high school or equivalent, or college or above), alcohol use (current or non-current), and smoking status (current or non-current)

*P $P<0.05$, * $P<0.001$

significantly associated to the development of T2DM in men $(1.50,1.02-2.21)$ and women $(2.02,1.35-3.02)$ with normal blood pressure.

Quartiles of all variables, baseline characteristics according to diabetes status at follow-up and risk for incident diabetes by quartile of HOMA-IR are shown in Additional file 1.

\section{Discussion}

This analysis was based on the premise that the greater the prevalence of insulin resistance within any diagnostic category, the more likely the incident rate of T2DM will increase. In other words, the fundamental question related to the likelihood of developing T2DM is not whether a person has a normal blood pressure or prehypertension, but whether or not they are insulin resistant. Before discussing the findings that support this hypothesis, it seems crucial to address the methods used to evaluate the association between insulin resistance and $\mathrm{T} 2 \mathrm{DM}$ in the two experimental groups. Insulin resistance in nondiabetic persons is associated with increased glycemia, hyperinsulinemia, and dyslipidemia, irrespective of whether they have normal blood pressure [16] or prehypertension [17]. Many other metabolic markers have been used to identify insulin resistance in nondiabetic persons, employing more sophisticated approaches [1822]. For example, HOMA-IR [18] is commonly used in population-based studies to provide a surrogate estimate of insulin resistance. However, HOMA-IR is a calculated value that combines within mathematical formula measurements of PI and PG concentrations. Since the 2-hour PG was being used in the analysis as one of the variables associated with insulin resistance, we thought it prudent not to use HOMA-IR which also includes a measurement of PG. Faced with the myriad associations between insulin resistance and multiple metabolic markers [18-22], it was decided to use the simplest available measurements of the three cardinal manifestations of insulin resistance in nondiabetic individuals: glycemia (2-hour PG), hyperinsulinemia (2-hour PI), and dyslipidemia (TG/HDL-C ratio). 
Table 4 Sex-stratified risk for incident diabetes by quartile of $2 \mathrm{~h}$ plasma insulin among participants with normal blood pressure and prehypertension

\begin{tabular}{|c|c|c|c|c|c|c|c|c|}
\hline & \multirow{2}{*}{$\begin{array}{l}\text { Number } \\
\text { at risk }\end{array}$} & \multirow{2}{*}{$\begin{array}{l}\text { Diabetes } \\
\text { cases }\end{array}$} & \multicolumn{2}{|l|}{ Unadjusted } & \multicolumn{2}{|l|}{ Model 1} & \multicolumn{2}{|l|}{ Model 2} \\
\hline & & & HR (95 \% Cl) & P for trend & HR (95 \% Cl) & $P$ for trend & HR (95 \% Cl) & P for trend \\
\hline \multicolumn{9}{|l|}{ Normal BP } \\
\hline \multicolumn{9}{|l|}{ Men } \\
\hline Quartile 1 & 446 & 43 & 1 (reference) & $<0.001$ & 1 (reference) & $<0.001$ & 1 (reference) & $<0.001$ \\
\hline Quartile 2 & 443 & 48 & $1.06(0.70-1.60)$ & & $1.07(0.71-1.61)$ & & $1.09(0.72-1.64)$ & \\
\hline Quartile 3 & 440 & 57 & $1.31(0.88-1.94)$ & & $1.34(0.90-1.99)$ & & $1.27(0.85-1.90)$ & \\
\hline Quartile 4 & 443 & 79 & $1.90(1.31-2.76)^{*}$ & & $1.94(1.34-2.82)^{*}$ & & $1.50(1.02-2.21)^{*}$ & \\
\hline \multicolumn{9}{|l|}{ Women } \\
\hline Quartile 1 & 541 & 36 & 1 (reference) & $<0.001$ & 1 (reference) & $<0.001$ & 1 (reference) & $<0.001$ \\
\hline Quartile 2 & 542 & 41 & $1.13(0.72-1.76)$ & & $1.14(0.73-1.79)$ & & $1.16(0.74-1.82)$ & \\
\hline Quartile 3 & 543 & 56 & $1.53(1.01-2.34)^{*}$ & & $1.60(1.05-2.44)^{*}$ & & $1.60(1.05-2.45)^{*}$ & \\
\hline Quartile 4 & 538 & 79 & $2.15(1.45-3.18)^{* *}$ & & $2.19(1.48-3.25)^{* *}$ & & $2.02(1.35-3.02)^{* *}$ & \\
\hline \multicolumn{9}{|c|}{ Prehypertension } \\
\hline \multicolumn{9}{|l|}{ Men } \\
\hline Quartile 1 & 241 & 35 & 1 (reference) & $<0.001$ & 1 (reference) & $<0.001$ & 1 (reference) & $<0.001$ \\
\hline Quartile 2 & 234 & 34 & $0.91(0.57-1.46)$ & & $0.89(0.56-1.43)$ & & $0.85(0.53-1.37)$ & \\
\hline Quartile 3 & 239 & 39 & $1.14(0.72-1.80)$ & & $1.14(0.72-1.80)$ & & $1.10(0.69-1.74)$ & \\
\hline Quartile 4 & 235 & 60 & $1.70(1.12-2.58)^{*}$ & & $1.78(1.17-2.71)^{*}$ & & $1.42(0.92-2.18)$ & \\
\hline \multicolumn{9}{|l|}{ Women } \\
\hline Quartile 1 & 205 & 24 & 1 (reference) & $<0.001$ & 1 (reference) & $<0.001$ & 1 (reference) & $<0.001$ \\
\hline Quartile 2 & 204 & 28 & $1.16(0.67-2.00)$ & & $1.15(0.67-1.99)$ & & $1.18(0.68-2.05)$ & \\
\hline Quartile 3 & 207 & 33 & $1.26(0.75-2.13)$ & & $1.25(0.74-2.12)$ & & $1.38(0.81-2.34)$ & \\
\hline Quartile 4 & 201 & 41 & $1.67(1.01-2.77)^{*}$ & & $1.70(1.02-2.82)^{*}$ & & $1.63(0.97-2.73)$ & \\
\hline
\end{tabular}

Model 1: adjusted for age

Model 2: adjusted for the variables in model 1 and fasting plasma glucose, body mass index, family history of diabetes (yes or no), education (less than high school, high school or equivalent, or college or above), alcohol use (current or non-current), and smoking status (current or non-current)

* $P<0.05$, ** $P<0.001$

Within the potential limitations of the markers selected for this analysis, the results in Tables 2, 3, 4 provide experimental support for the hypothesis that the more insulin resistant an individual, whether they had normal blood pressure or prehypertension, the greater their risk of developing T2DM. Specifically, the greater was the magnitude of the manifestations of insulin resistance, whether it is glycemia, hyperinsulinemia, or dyslipidemia, the more likely the development of T2DM. Furthermore, these general findings obtained irrespective of sex and clinical diagnosis.

Although the findings in Tables 2, 3, 4 are comparable in that manifestations of insulin resistance were significantly associated with incident T2DM in both experimental populations, it should be noted that metabolic characteristics of insulin resistance were accentuated in patients with prehypertension [Table 1]. By selection, blood pressure was also elevated in those with prehypertension. These considerations bring into focus the question of causality raised by Emdin and colleagues [1]: does elevated blood pressure, per se, increase risk of T2DM, or do abnormalities that increase risk of hypertension also increase risk of T2DM? This question cannot be answered by the current data, but a strong biological argument can be made in support of the second alternative. For example, normotensive, first-degree relatives of patients with high blood pressure are insulin resistant when compared to normotensive individuals without a family history of hypertension [23-25], and surrogate markers of insulin resistance predict incident hypertension [26, 27]. Finally, there is considerable evidence that resistance to insulin-mediated glucose uptake is increased in patients with essential hypertension when compared to appropriate control groups [28-30]. On the other hand, there are important differences in the relationship between insulin resistance and T2DM as compared to its relationship to hypertension [5]. Thus, the overwhelming majority of patients with T2DM are insulin resistant, whereas only approximately $50 \%$ of patients with essential hypertension, treated or untreated, are insulin resistant [31], and 
these differences in prevalence may help explain why it has been so difficult to even establish the existence of a relationship between elevated both pressure and T2DM.

There are limitations to our study that should be discussed. Firstly, we conducted a post hoc analysis of epidemiological data collected for other purposes. In addition, it is possible that our findings in inhabitants of Korea may not apply to other racial/ethnic populations. Thirdly, direct quantification of insulin resistance was not available, and our analysis was based on use of differences in dysglycemia, hyperinsulinemia, and dyslipidemia, three metabolic abnormalities characteristic of insulin resistance, to evaluate the association between insulin resistance and incident T2DM. Perhaps the most appropriate way view our findings is as hypothesis-generating; leaving it to future studies to validate, or discard, the formulation that the increased incidence of T2DM in patients with essential hypertension is related to the increased prevalence of insulin resistance in this clinical syndrome.

\section{Conclusion}

These data demonstrate that the subset of individuals with the greatest degree of insulin resistance, whether they have normal blood pressure or prehypertension, is at increased risk to develop T2DM. As such, they are consistent with the suggestion that it is the increased prevalence of insulin resistance in patients with essential hypertension that accounts for their increased risk of T2DM. Put more simply, since prevalence of insulin resistance is increased in patients with essential hypertension [5, 28-31], and insulin resistance is a powerful predictor of T2DM [3, 4], it should not be surprising, as reported by Emdin, et al. [1], that patients with essential hypertension are at increased risk to develop T2DM. What the current results do is provide evidence that the same phenomenon seems to also be true of patients with prehypertension.

\section{Additional file}

Additional file 1. Quartiles of all variables, baseline characteristics according to diabetes status at follow-up and risk for incident diabetes by quartile of HOMA-IR.

\section{Authors' contributions}

KCS, HYP, MJK analyzed the experimental data, performed the statistical analysis, and participated in data interpretation and manuscript preparation. GR reviewed the results as prepared by KCS, and was actively engaged in interpretation of the data and preparation of the manuscript. All authors read and approved the final manuscript.

\section{Author details}

${ }^{1}$ Division of Cardiology, Department of Medicine, Kangbuk Samsung Hospital, Sungkyunkwan University School of Medicine, \#108, Pyung Dong, Jongro-Ku, Seoul 110-746, Republic of Korea. ${ }^{2}$ Division of Cardiovascular and Rare Diseases, Center for Biomedical Science, Korea National Institute of Health, 187
Osongsaengmyeng 2-ro, Osong-eup, Heungdeok-gu, Cheongju, Chungbuk 361-951, Republic of Korea. ${ }^{3}$ Division of Cardiovascular Medicine, Stanford University School of Medicine, Stanford, CA 94305, USA.

Competing interests

The authors declare that they have no competing interests.

Received: 2 February 2016 Accepted: 15 March 2016

Published online: 22 March 2016

\section{References}

1. Emdin CA, Anderson SG, Woodward M, Rahimi K. Usual blood pressure and risk of new-onset diabetes: evidence from 4.1 million adults and a meta-analysis of prospective studies. J Am Coll Cardiol. 2015:66(14):1552-62.

2. Kim MJ, Lim NK, Choi SJ, Park HY. Hypertension is an independent risk factor for type 2 diabetes: the Korean genome and epidemiology study. Hypertens Res. 2015;38(11):783-9.

3. Reaven GM. Banting lecture 1988. Role of insulin resistance in human disease. Diabetes. 1988:37(12):1595-607.

4. Lillioja S, Mott DM, Spraul M, Ferraro R, Foley JE, Ravussin E, Knowler WC, Bennett PH, Bogardus C. Insulin resistance and insulin secretory dysfunction as precursors of non-insulin-dependent diabetes mellitus. prospective studies of Pima Indians. N Engl J Med. 1993;329(27):1988-92.

5. Reaven GM. Relationships among insulin resistance, type 2 diabetes, essential hypertension, and cardiovascular disease: similarities and differences. J Clin Hypertens. 2011;13(4):238-43.

6. Kim BG, Park JT, Ahn Y, Kimm K, Shin C. Geographical difference in the prevalence of isolated systolic hypertension in middle-aged men and women in Korea: the Korean Health and Genome Study. J Hum Hypertens. 2005;19(11):877-83.

7. Friedewald WT, Levy RI, Fredrickson DS. Estimation of the concentration of low-density lipoprotein cholesterol in plasma, without use of the preparative ultracentrifuge. Clin Chem. 1972;18(6):499-502.

8. American Diabetes A. Diagnosis and classification of diabetes mellitus. Diabetes Care. 2010;33(Suppl 1):S62-9.

9. Chobanian AV, Bakris GL, Black HR, Cushman WC, Green LA, Izzo JL Jr, Jones DW, Materson BJ, Oparil S, Wright JT Jr, et al. The Seventh Report of the Joint National Committee on Prevention, Detection, Evaluation, and Treatment of High Blood Pressure: the JNC 7 report. JAMA. 2003;289(19):2560-72.

10. Yeni-Komshian H, Carantoni M, Abbasi F, Reaven GM. Relationship between several surrogate estimates of insulin resistance and quantification of insulin-mediated glucose disposal in 490 healthy nondiabetic volunteers. Diabetes Care. 2000;23(2):171-5.

11. Hollenbeck CB, Chen N, Chen YD, Reaven GM. Relationship between the plasma insulin response to oral glucose and insulin-stimulated glucose utilization in normal subjects. Diabetes. 1984;33(5):460-3.

12. Laws A, Reaven GM. Evidence for an independent relationship between insulin resistance and fasting plasma $\mathrm{HDL}$-cholesterol, triglyceride and insulin concentrations. J Intern Med. 1992;231(1):25-30.

13. McLaughlin T, Reaven G, Abbasi F, Lamendola C, Saad M, Waters $D$ Simon J, Krauss RM. Is there a simple way to identify insulin-resistant individuals at increased risk of cardiovascular disease? Am J Cardiol. 2005;96(3):399-404.

14. Salazar MR, Carbajal HA, Espeche WG, Leiva Sisnieguez CE, Balbin E, Dulbecco CA, Aizpurua M, Marillet AG, Reaven GM. Relation among the plasma triglyceride/high-density lipoprotein cholesterol concentration ratio, insulin resistance, and associated cardio-metabolic risk factors in men and women. Am J Cardiol. 2012;109(12):1749-53.

15. Salazar MR, Carbajal HA, Espeche WG, Aizpurúa M, Leiva Sisnieguez CE, March CE, Balbin E, Stavile RN, Reaven GM. cardiovascular disease risk and outcome: use of the plasma triglyceride/high-density lipoprotein cholesterol concentration ratio versus metabolic syndrome criteria. J Int Med. 2013;273:595-601.

16. Zavaroni I, Bonora E, Pagliara M, Dall'Aglio E, Luchetti L, Buonanno G, Bonati PA, Bergonzani M, Gnud L, Passeri M, Reaven GM. Risk factors for 
coronary artery disease in healthy persons with hyperinsulinemia and normal glucose tolerance. N Engl J Med. 1989;320:702-6.

17. Knobler H, Abbasi F, Lamendola C, Reaven GM. Insulin resistance and cardiovascular disease risk factors in subjects with prehypertension. Diab Vasc Dis Res. 2011;8:41-6.

18. Matthews DR, Hosker JP, Rudenski AS, Naylor BA, Treacher DF, Turner RC Homeostasis model assessment: insulin resistance and beta-cell function from fasting plasma glucose and insulin concentrations in man. Diabetologia. 1985;28(7):412-9.

19. Joseph J, Svartberg J, Njølstad I, Schirmer H. Risk factors for type 2 diabetes in groups stratified according to metabolic syndrome: a 10-year follow-up of the Troms $\varnothing$ study. Eur J Epidemiol. 2011;26:117-24.

20. Imamura F, Mukamal KJ, Meigs JB, Luchsinger JA, Ix JH, Siscovick DS, Mozaffarian D. Risk factors for type 2 diabetes mellitus preceded by $\beta$-cell dysfunction, insulin resistance, or both in older adults: the Cardiovascular Health Study. Am J Epidemio. 2013;15(177):1418-29.

21. Hwang YC, Hayashi T, Fujimoto WY, Kahn SE, Leonetti DL, McNeely MJ, Boyko EJ. Differential Association between hdl subclasses and the development of type 2 diabetes in a Prospective Study of Japanese Americans. Diabetes Care. 2015;38:2100-5.

22. Guo F, Garvey WT. Cardiometabolic disease risk in metabolically healthy and unhealthy obesity: stability of metabolic health status in adults. Obesity (Silver Spring). 2016;24:516-25.

23. Allemann $Y$, Horber FF, Colombo M, Ferrari P, Shaw S, Jaeger P, Weidmann P. Insulin sensitivity and body fat distribution in normotensive offspring of hypertensive parents. Lancet. 1993;341(8841):327-31.
24. Facchini F, Chen YD, Clinkingbeard C, Jeppesen J, Reaven GM. Insulin resistance, hyperinsulinemia, and dyslipidemia in nonobese individuals with a family history of hypertension. Am J Hypertens. 1992;5(10):694-9.

25. Ferrari P, Weidmann P, Shaw S, Giachino D, Riesen W, Allemann Y, Heynen G. Altered insulin sensitivity, hyperinsulinemia, and dyslipidemia in individuals with a hypertensive parent. Am J Med. 1991;91(6):589-96.

26. Raitakari OT, Porkka KV, Rönnemaa T, Knip M, Uhari M, Akerblom HK, Viikari JS. The role of insulin in clustering of serum lipids and blood pressure in children and adolescents. The cardiovascular risk in Young Finns Study. Diabetologia. 1995;38:1042-50.

27. Zavaroni I, Bonini L, Gasparini P, Barilli AL, Zuccarelli A, Dall'Aglio E, Delsignore $\mathrm{R}$, Reaven GM. Hyperinsulinemia in a normal population as a predictor of non-insulin-dependent diabetes mellitus, hypertension, and coronary heart disease: the Barilla factory revisited. Metab, Clin Exp. 1999;48(8):989-94.

28. Ferrannini E, Buzzigoli G, Bonadonna R, Giorico MA, Oleggini M, Graziadei L, Pedrinelli R, Brandi L, Bevilacqua S. Insulin resistance in essential hypertension. N Engl J Med. 1987;317(6):350-7.

29. Pollare $\mathrm{T}$, Lithell $\mathrm{H}$, Berne $\mathrm{C}$. Insulin resistance is a characteristic feature of primary hypertension independent of obesity. Metab, Clin Exp. 1990;39(2):167-74.

30. Shen DC, Shieh SM, Fuh MM, Wu DA, Chen YD, Reaven GM. Resistance to insulin-stimulated-glucose uptake in patients with hypertension. J Clin Endocrinol Metab. 1988;66(3):580-3.

31. Lima NK, Abbasi F, Lamendola C, Reaven GM. Prevalence of insulin resistance and related risk factors for cardiovascular disease in patients with essential hypertension. Am J Hypertens. 2009;22(1):106-11.

\section{Submit your next manuscript to BioMed Central and we will help you at every step:}

- We accept pre-submission inquiries

- Our selector tool helps you to find the most relevant journal

- We provide round the clock customer support

- Convenient online submission

- Thorough peer review

- Inclusion in PubMed and all major indexing services

- Maximum visibility for your research

Submit your manuscript at www.biomedcentral.com/submit
() Biomed Central 